\title{
The role of questioning in writing tutorials: a critical approach to student-centered learning in peer tutorials in higher education
}

\author{
Paul Nwati Munje, Robert Doya Nanima and Sherran Clarence
}

\begin{abstract}
Peer tutoring in higher education aims to enhance student learning, and confidence. In writing centres, peer writing tutors use critical questioning to make the tutorial sessions student-focused and productive. The nature of questions influences the outcomes of the tutorials, yet research has not devoted sufficient time to unpacking what form this questioning takes, and the potential value for students and tutors. This paper explores the kinds of questions asked, the challenges posed to students and tutors, and implications for the learning process. Tutors' experiences during tutorials and their reflections in written reports are used to unpack and explore questioning in tutorials. The paper highlights questioning as relevant in writing centre spaces due to its central role in shaping student learning about writing. The findings have relevance for peer tutoring in higher education generally, and indicate the importance of peer tutors learning to use questions to engage effectively with students.
\end{abstract}

\section{Introduction}

University writing centres are broadly understood, in South Africa and around the world, to provide a place where students and staff focus on the development and academic support of student learning through writing. They are usually centrally located, rather than housed in particular faculties or departments (Yeats, Reddy, Wheeler, Senior, \& Murray, 2010), and typically work with students across the disciplines, at both under- and post-graduate levels. Essentially, writing centres place themselves within a particular discourse, against remediation or 'fixing' poor students' writing (Clarence, 2011; O'Sullivan \& Cleary, 2014). Drawing on discourses and theoretical underpinnings such as those implicated in Academic Literacies, most writing centres in South Africa characterise writing as a social, value-laden act of meaning making within the academy (Archer, 2010; Dison \& Clarence, 2017). Writing is informed by the disciplinary knowledge students are writing about, the ways in which that knowledge is created, debated and disseminated in these disciplinary communities, and the ways this knowledge and writing is valued, shaped, constructed and understood (Jacobs, 2015). Writing is not a discrete 'skill'; it is a practice that must be developed and learned over time, and in community and conversation with others: peers, tutors and lecturers (Hathaway, 2015). 
Constructed within this framing and positioning of writing centres, peer writing tutorials, or consultations as they are often known, are not about telling or teaching students the 'right' ways to write. Peer tutors do not assume the role of writing authority, dispensing writing instructions or prescriptions to student writers who are positioned as novices in relation to the peer tutor as 'expert' (Hathaway, 2015). Rather, peer tutors position themselves alongside students, physically and figuratively, sitting beside them in the writing centre, and working with them to question, challenge, support and advise as they engage in the difficult task of revising and rethinking their written work. In South Africa, as in other contexts where admission is inclusive, such as the UK (see Deane \& Ganobcsik-Williams, 2012), writing centres work with a heterogeneous student body, students from a range of home and school backgrounds with different levels of preparedness for tertiary study; students with home languages other than English; students with different kinds of exposure in their prior schooling to reading, writing and feedback; and so on. Writing centres are designed to embrace and foster this heterogeneity, working with students in ways that celebrate and include their individualism, while walking a cautious line between this and helping students to better 'fit in' with the rules and conventions of writing and thinking in the academy (Carter, 2009; Nichols, 2017). Thus, the ways in which peer tutors create conversations with students, through the kinds of questions they pose and probe with, is a vital aspect of how a writing centre works within this context and its tensions.

This implies that peer writing tutors need significant support from writing centre coordinators tasked with developing and supporting these tutors. Therefore, the environment for learning created in a writing centre should be one that facilitates generative conversations about writing and knowledge-making across a range of writing tasks, disciplines, and levels of writing experience and ability. Since questioning is at the centre of writing tutorials, it is important, then, to consider its nature: what kinds of questions we ask, how and when we ask them, and whether and how this process invites students to be part of their own learning process in productive and empowering ways. This paper attempts to closely and critically unpack and understand the role and nature of questioning in peer writing tutorials within a South African higher institution's writing centre, and consider the implications of the findings for writing centres, and peer tutoring more generally. More specifically, the paper addresses the following research question: What types of questions create space for student writers to become part of the writing process? In other words, how do we, through questioning, create spaces for student writers to take ownership of their writing, reflect on the process of creating a piece of writing, and learn about themselves as writers in ways that enable further growth and learning?

\section{Tutoring, questioning and learning in higher education}

The concept of questioning in learning events, such as tutorials, can be defined and applied in varied contexts. Questioning is an important tool used by peer tutors, specifically in writing centres, to create an interactive space with student writers that encourages engagement, participation, and enhances the achievement of stated or implicit goals (Limberg, Moday \& Dyer, 2016). Capdevielle (2012) sees questioning during writing centre tutorials as an age-old tradition that needs to be nurtured because of its unquantifiable value, 
especially in ensuring that skills achieved are valued beyond a particular session. Essentially, opening a peer writing consultation with questions that draw the student into the conversation, and make them feel that their voice will be heard, valued and included, sets up a productive space for conversations about writing (Capdevielle, 2012). This approach enhances what writing centres, and peer writing tutors advocate. This approach could enable students to obtain effective feedback to improve their understanding and execution of their tasks, feedback that is forward-looking, and aids students' development and the learning process (Deyi, 2011; van Heerden, Clarence, \& Bharuthram, 2017).

According to Limberg et al. (2016), questioning has both 'pedagogical and organizational tenets' and is used by tutors to tap into the knowledge of student writers within writing centre spaces. Pedagogically, questioning directs the student to reflect on a given task on their own and formulate answers with little external influence (O'Sullivan \& Cleary, 2014). The organizational aspect, on its part, calls for the right questions to be asked at the right time during the course of the tutorial. The kind of questions asked, how they are framed, the context, and the phase of the consultation in which they are asked, are suggested to be critical elements in determining the nature and outcome of a consultation (Brown, 2008; Limberg et al., 2016). Brown (2008) notes that if tutors ask the wrong questions or focus on criticising the work of students rather than asking leading and encouraging questions, it is probable that students will feel judged and insecure about their writing, consequently withholding relevant ideas that can potentially take the consultation forward.

The questioning process in writing centre spaces during tutorials therefore needs to be friendly, dialogical and open. The intention is to assist student writers uncover their own talents, as well as their basic knowledge and understanding of the topic or text under discussion (O'Sullivan \& Cleary, 2014). Thompson (2009) suggests the need for writing tutors to ask questions that will properly engage student writers in a process of self-reflection and self-discovery, assisting them to identify gaps in their own writing without too much intervention. For this reason, rather than pointing out the errors in the student's draft or text, questions should be framed with the intention of leading student writers on a critical thinking path of increasingly independent problem identification and problem-solving. Here, the focus is on knowledge building, increased understanding, and confidence.

Limberg et al. (2016) indicate that different kinds of questions play particular roles at different stages of the consultation and produce varying outcomes. For example, every successful consultation is shaped by the nature and outcome of introductory questions essential icebreakers (Limberg et al., 2016) - which can either make or break a consultation session (Harris, 1995). Harris (1995) suggests that introductory questions ought to be framed to portray the tutor as a peer that is willing to help and listen with non-judgmental intent (see also Brown, 2008). This welcoming opening to writing tutorials has the potential to cater for the emotional challenges of especially first-year university students, who are often affected by varying prior schooling experiences that may have implications for their 
perceptions of studying, learning spaces, and approaches to learning (Beard, Clegg, \& Smith, 2007). For this reason, tutors are not to expected begin all tutorials in the same way with all student writers they encounter, even when they see many students about the same writing task. Apart from making the student feel at ease, introductory questions should also assist a tutor to tap into the student's prior knowledge and understanding of the task at hand, and also activate their thinking abilities. The questions asked at this stage of the consultation make the student the 'primary agent' in the writing tutorial, and the owner of their own work, rather than making the tutor the focus or task owner (Brooks, 1991, p. 2; MitoumbaTindy, 2017). This makes it relevant for tutors to carefully determine how to use questioning to open a conversation with a student writer. Questioning thus ought to act as a valuable tool to assist student writers during tutorials to learn to identify writing gaps or missteps, discuss these constructively, and learn to revise their writing effectively, with the tutor as peer advisor rather than instructor (Mitoumba-Tindy, 2017).

The role of the tutor as advisor and interlocutor, rather than surrogate lecturer is central to this dialogic, engaged view of tutorials led by questions, rather than answers. If tutors take on too directive a role, students will be unable to become the primary agents in writing tutorials, or the owners of their texts. Thus, questioning in writing centre spaces should assist 'writing peer tutors/consultants ... to play the role of writing advisor and peer mentor who can offer students writing guidance, probe their thinking and question their clarity of response to specific tasks they are working on' (Dison \& Clarence, 2017, p. 8). In effect, questioning should give student writers a platform to shed the passive role they may more readily assume in their lecture halls and become more active, independent, and creative thinkers.

When student writers feel settled and convinced that they are in an appropriate environment for peer learning, they may be moved to ask valuable task and writing related questions that could assist them to see their writing with fresh perspectives and insights. Thompson and Mackiewicz (2014) are of the opinion that questioning in writing centre tutorials is meant to indirectly guide students through their own reasoning, thus consultation sessions could be made more productive by giving students the space to freely ask tutors questions about their work. The aim of writing centre work is to enhance the writing process, and to equip the writer with longer-term confidence, skill and understanding to assist them progressively become better academic writers (Dison \& Mendelowitz, 2017). Thus, while the requirements of the task should be taken into consideration and task-specific questions should lead on from the students' assessment of their own aims, challenges and specific needs, it is suggested that tutors should encourage students to also think more broadly about their writing (Brooks, 1991; Shabanza, 2017). In all consultations or tutorials, regardless of the task at hand, the questioning process should be two-way: students must be able to ask tutors questions, just as tutors should strive to use appropriate questions to engage, probe, challenge and advise student writers. Ultimately, students should leave a writing tutorial feeling they have discovered their own solution or way forward to the writing issues at hand, and clarified their own doubts and views on their assignment. 


\section{Positioning the UWC writing centre}

The need to improve the quality of education at the University of the Western Cape (UWC) by way of assisting students in their learning endeavours began in the 1980 s with the establishment of the Academic Development Programme (ADP). This was meant to bridge the gap between the requirements of university studies and the resources and challenges students brought with them from school to university. Although the programme unfortunately never achieved its objectives (Wolpe, 1995), it created a basis for the establishment of the Writing Centre. South Africa's democratic dispensation in 1994 ushered in a new era in all spheres of society, including higher education. 1994 also marked the opening of the UWC Writing Centre, as a response to the intake of larger numbers of students from different backgrounds, and especially black students who were previously denied access to higher education institutions (Habib, 2016; Reddy, 2004). In effect, this introduced a process that changed the way in which teaching, learning and student support has been conceived and enacted at UWC, as the Writing Centre was among several measures put in place to ensure quality education.

The UWC Writing Centre, like many others, was initially housed within a larger academic development centre, which was later closed. Since then it has existed independently, although with the support of the divisions for teaching and learning development within the university. Although traditionally conceived as a remedial space to teach students who struggle to write effectively, much like its counterparts in other universities, the UWC Writing Centre has evolved beyond this limited initial role (see Archer, 2010; Nichols, 2017). The UWC Writing Centre has reimagined itself as a space in which students and peer tutors can meet to discuss writing tasks, and some of the related challenges of tertiary study, without students fearing they will be judged and found lacking or deficient in some way. Striking back against dominant deficit discourses that position students' underpreparedness as the key problem, rather than universities' underpreparedness for such diverse student bodies and experiences, the UWC Writing Centre underpins its work theoretically and ideologically with Academic Literacies (Lillis, Harrington, Lea, \& Mitchell, 2015), as outlined earlier. In so doing, it has worked, and continues to work, to cast itself in the role of academic support for all student writers at the university, regardless of prior or present levels of competence in writing.

Further, the UWC Writing Centre aligns itself with writing centre work locally and globally by creating a space for students to not only learn how to write effectively in and across the disciplines, but also where the conventions and rules that shape writing can be unpacked, made visible, and even challenged at times. This is challenging work, as it requires the Centre to walk what is often a fine line between being there for the students, but also being there for the university that funds its existence; and often what students need and what the university wants are at odds (see Carter, 2009; Dison \& Clarence, 2017).

Students need to be guided through the learning processes of writing, and that takes time because these processes are not linear. Universities want higher throughput rates and 
better pass marks (Lewin \& Mawoyo, 2014), and often work towards these from a deficit discourse. Universities perceive proficiency in academic writing as a 'skill' that students ought to be able to learn early on and simply perfect as they go, or even have it with them, when they enter university (Bock, 1989). This discourse places writing problems squarely on the shoulders of students, denying a process-oriented approach to writing (see Smit, 2012; O'Shea, Lysaght, Roberts, \& Harwood, 2016; on deficit discourses). According to Bourdieu and Passeron (1990), an approach that engages with students from their current position and helps them develop proficiency or ability is preferred. Bourdieu and Passeron (1990) argue that English language is no one's mother tongue regardless of prior home and school background and that all students, although to varying degrees, need guidance and support in becoming academically literate.

The use of questions to guide these process-oriented, student-centred writing tutorials is key to the way the UWC Writing Centre challenges the deficit discourse to create a space where all writers, and all writing, are welcome. Its unique approach to questioning creates a platform of engagement that can motivate and empower student writers as they become increasing aware of the need to take ownership of and responsibility for their learning and writing. As such,

different types of questions are asked during writing tutorials based on the context of the tutorial and its purpose. These questions are usually not pre-planned, considering that student challenges and circumstances vary. The responses and outcomes at each stage are based on how the questions are framed and the emotional state of the student during the tutorial. Certain questions and responses assist to redirect the framing of follow-up questions, and also play an important role in taking the consultation forward. However, the experience and skill of the tutor determines the ways in which questions are worded, timed and posited to students, and how in turn questions are answered and built into the ongoing conversation. The questions asked are commonly grouped into introductory, task-related, and more general writing-related questions.

\section{Methodology}

This paper draws on data from the authors' peer tutoring experiences, their own reports written on tutorials with students, and students' anonymous feedback after consultation sessions. The paper explores the types of questions that assist student writers to: get involved in the writing process; take ownership of their writing; be able to identify gaps in their writing; and generally be able to reflect on and hopefully learn more about academic writing. Ethical clearance for this project was granted by the university, under the auspices of a larger project on tutor development within the university. The writers made use of individual reflective journals to piece together conversations and experiences with students. An effort was made to include reflections on student reactions and responses during tutorials, their ability to ask questions, and their initiative to answer questions and take ownership of their work. 
The data used in this paper was not 'analysed' as such using any particular approach. Rather, different kinds of questions were noted, and recorded from the data sources, and then organised into the three categories mentioned above: introductory, task-related, and more general writing-process-related questions. The authors then discussed these categories, further refining them in relation to the data, before deciding on the framework for the following section. The data is thus used to form a basis for looking critically at the different kinds of questions that are asked most frequently in peer writing tutorials, and how these can facilitate productive conversations with students about their writing.

\section{Findings and discussion}

\section{Introductory questions}

To begin with, introductory questions are often used as ice-breakers and are asked with the intention of making students feel welcome and comfortable. Peer tutors should be able to ask questions that develop closeness with student writers, in a holistic perspective (Jones, Garralda, Li and Lock, 2006). At the UWC Writing Centre, the form and direction of the introductory questions is at the discretion of the writing tutor. However, the training and development programme offered to tutors throughout the year encourages them to 'read' the student and determine how best to start a consultation; for example, the student and tutor may be meeting for the first time, and the student may be apprehensive, or they may have worked together before and thus can start the conversation from an established base. Tutors are thus trained to be sensitive and alert to the way students respond to the initial ice-breakers, and to switch direction or stop depending on the reaction of the student.

A common opener to a writing tutorial:

- Tutor: Hi, welcome to the writing centre. How are you today?

- Student: I'm okay, thank you.

- Tutor: Have you been here before? Do you know anything about us, what we do, how we work?

- $\quad$ Student: No, this is my first time.

- Tutor: How are you hoping to be helped today? What are you struggling with in your writing?

- $\quad$ Student: I need someone to help me with my essay, see if I am on the right track.

- Tutor: Most students who come here ask for that kind of help, so you are not alone here. Let's have a look, and see what the task is about and where we can go from there. I'm going to ask questions, and you can ask questions too, and ideally we're going to talk about your writing so that you leave here knowing what to do next to work on it. Okay?

Questions that invite students to define the problem they need help with, and start to think about where they are starting from in a process of developing as writers are designed to both welcome the student, and gently open a reflective space of the writing 
tutorial. Students new to the Writing Centre tend to expect to come in and meet a tutor who will correct their work, or tell them how to 'fix' their essay. Thus, the introduction must accomplish the task of settling the student in, and informing them gently that they will need to participate in the tutorial to improve their writing.

The challenge attached to introductory questions is that tutors may need to spend more time than may be desirable - given that tutorials are only an hour long-settling down the student, especially in cases where students seem to be struggling, or does not have a clear understanding of what help they are looking for. In these cases, tutors may inadvertently create too large a space for student writers to pour out their problems, in terms of writing or university life in general, potentially derailing the consultation and making it difficult to refocus on the writing process. Although such a friendly rapport is important, care needs to be taken not to make the tutorial too social, such that time is taken away from the important academic work. This can be a particular challenge for tutors within a space such as a writing centre, where emphasis is placed on undoing the hierarchical power relations inherent in lecturer-student relationships, and sharing the control over the content and pace of the tutorial with the student (Mitoumba-Tindy, 2017). Thus, while tutors always want to be welcoming and sociable, it is important to balance creating a space in which students feel comfortable to talk and share, with focusing on the academic work at hand, so that students and tutors are able to work effectively together on the writing.

In one consultation in 2016, the second author engaged with a student and established through introductory and task-related questions that the student did not understand the task and was not prepared for the consultation session. This posed a risk of the tutor answering the task for the student, or offering feedback that would make the student feel like she was being judged on her writing. In his report, the tutor stated:

The student did not understand the task and the draft presented was not in line with the requirements specified by the concerned lecturer. For this reason, the tutor assisted the student on task analysis and advised her to do further reading and come back for a follow-up session the following Friday.

When the student returned for the follow-up session, the engagement was fruitful. This was reflected by the nature of interaction between the peer tutor and the student. The student felt more comfortable, confident and interactive. A report by the tutor after the follow-up session stated:

This was a follow-up to an earlier appointment that had been scheduled from the previous week. The kinds of questions and answers that emerged from the session proved that the student appreciated what was done during the first consultation. The student was able to use task analysis skills learnt during the first session. Also her ability to answer and ask questions proves that she had done extensive reading as advised. 
This is an indication that the introductory questions helped to orient the student towards taking ownership of her own writing, and also to the ways in which the Writing Centre seeks to assist student writers. The student was able to learn and use task analysis skills, and was also more able to engage with the feedback in the course of the session, as a result of being more prepared to take part in the tutorial as a co-creator of the space, rather than a passive recipient of writing assistance.

\section{Task-related questions}

Tutors at the UWC Writing Centre utilise task-related questions to uncover and discuss students' knowledge and understanding of the task or assignment at hand. Such questions encourage student writers to think about their task from different perspectives, and to bring relevant disciplinary knowledge into the conversation that will assist them to revise the written work accordingly. The framing of the questions and student responses reveals the depth or level of students' understanding or lack thereof. The deduction is made by comparing what they say verbally and what is in their written draft; the latter is used by peer tutors to prepare ahead for the meeting with the student. The data revealed different groupings of task-related questions: task analysis questions; conceptual/terminology questions; reading and research questions; and organisation of ideas/structure questions. Peer tutors do ask questions about referencing, but as this is not a primary focus of any writing tutorial (unless it is the only issue a student needs help with) this did not emerge as a significant category.

Task analysis questions are focused on tapping into the students' understanding of the specific conceptual or task-related keywords, as well as direction or instruction words in the specific assignment question or task. The assumption here is that, if a tutor can help the student to clearly understand the specific instructions and requirements in the assignment/task (and generally many students struggle to analyse task briefs), they will be better able to accurately analyse the task, and plan a competent written response. Since students are expected to analyse their task briefs and construct an answer that responds to the specific demands of the lecturer, writing tutors also pose questions at this stage to understand whether students' verbal analysis and written drafts are in harmony and meet these demands. Where verbal explanations are a mismatch with the written assignment, follow-up questions are then asked to assist students to self-identify gaps in their own reasoning and writing - these questions may then segue into questions about key terminology and concepts involved, and even reading and research needs and plans. At this stage, the student is able to focus on the most relevant or important parts of the assignment that needs to be revised as they are supported by peer tutors to rethink their response to the assignment brief.

A fairly typical snippet of task-related questioning:

- Tutor: Let's have a look at your task. What is it that you are required to do here with this assignment?

- $\quad$ Student: I have to write an essay on Macbeth. 
- Tutor: Okay, yes. What aspect of Macbeth are you focusing on here - it's a long play?

- $\quad$ Student: We have to look at the part of Lady Macbeth, where she is telling him to kill the king.

- Tutor: Okay. So is that an interesting part of the play: What happens there?

- Student: <answers with a brief account of the conversation in the play between Macbeth and Lady Macbeth>.

- Tutor: Right. So, what does your task ask you to say about this part of the play? Do you have to analyse what they are saying? Or do you have to relate it to what comes before or after this in the play?

- Student: We have to relate it to the rest of the play, to show how Lady Macbeth makes Macbeth do what he did.

- Tutor: Okay, so you are positioning this extract within the play, and then writing about what it means for what comes after, the events that happen after Macbeth kills the king?

- $\quad$ Student: Yes, I think so.

- Tutor: And, how have you tried to do this, in your draft here? Can you talk me through the draft, and how you feel you have answered this question?

- Student: <begins to explain the draft to the tutor>.

- Tutor: Do you think what you have just said is related to what is in your draft?

- $\quad$ Student: I think so.

- Tutor: Okay let us compare what you have said to what is in your draft, and work from there on possible revisions and changes you can make to improve it.

This snippet highlights aspects of task analysis questioning, and then moving the student into the draft itself, leading the conversation into questions about terminology, reading and research, the organisation and selection of ideas and how these are connected, and so on. Importantly, it highlights that tutorials cannot necessarily follow a linear, step-by-step structure, where questions can be posed in a 'tick-box' form, which is, starting at one predetermined point and moving steadily through a set of questions in a logical' order. As the writing process is non-linear, so are conversations about writing. The important thing to note in this exchange is the tutor pushing the ownership of the writing onto the student, using questions, and repeating back to the student key parts of their responses, to move the conversation onto the writing, and the ways in which it has evolved thus far. It should be noted that it is a significant task to ensure that the right kinds of questions for this student, and this draft, are posed, and the desired outcomes are therefore achieved for every student and for every consultation. Students come with different expectations of tutors and the writing centre, and these do not always align with our ways of working. Many students are open to the question-and-answer, dialogic mode of working, even if they arrived wanting to have their writing 'fixed'. But some are resistant, feeling perhaps that this asks too much of them, or is too open-ended where they may be struggling with the implied independence of thinking and 
writing post-tutorial. These varied demands, and thus the changeable tone of tutorial sessions, can result in tutors pointing out errors in the student's draft, or telling the student how to revise a particular passage or paragraph, rather than posing leading questions that ought to prompt engagement, reflection, and self-identification of (at least some of the) revisions needed. Some tutors may be tempted to act as surrogate lecturers or disciplinary tutors, especially in instances where students demonstrate limited knowledge of the task at hand, or do not demonstrate the ability to consistently answer questions designed to direct or prompt their own thinking. A report after consultation session, the tutor stated:

The session focused on task interpretation due to the gap between the student's draft, verbal narration and what the task requires. Evidently, the student did not pay attention to the task guide, and as such did not interpret and answer the question as expected. Attempts were therefore made to guide the student through the necessary steps and requirements. After every explanation, the student was given an opportunity to jot down the necessary information to use in his post tutorial revision and rewriting. Since the student had a basic idea of the content, it was easier to guide her through the process. After the session she was advised to redo the assignment following guiding steps provided, and to come in for a follow up consultation the following week.

In another report after consultation, the same tutor stated that:

The student came to the session needing help with spelling and grammar for an essay that has been marked by his subject tutor. He was hesitant to answer task-related questions, because he did not attend to the comments of his subject tutor. The student's reaction was evident that he expected the writing tutor to attend to the comments of the subject tutor on his behalf. Considering that the subject tutor was familiar with the content of the essay, I focused on asking questions related to task analysis, so as to interrogate the student's understanding of the task and not the comments of his tutor. Attending to the tutor's comments would have been tantamount to me editing the student's work, rather than guiding him through the writing process.

Although the approach by this tutor would potentially assist such students to improve that particular assignment, the primary objective of a writing tutorial as creating a space for students to acquire necessary abilities and knowledge with potentials for replicability or further development is undermined. Students in such circumstances may be constrained in developing a level of confidence in their ability to improve their writing without such 'step-by-step' guidance, creating a dependency on the writing centre. This further undermines the focus on writing as a social, community-oriented activity that develops over time, rather than as one dependent on acquiring the right skills for a particular task. Thus, in addition to questions about the task at hand, peer tutors also ask more generalised writing-related questions that have in mind longer-term writing development and knowledge building. 


\section{Writing-related questions}

The intention of writing-related questions is to explore and develop students' knowledge of academic writing more broadly, particularly through focusing not only on what we need to write in higher education and how, but also why we write in particular forms or styles. The questions at this stage are geared towards potentially developing students' knowledge of academic writing beyond the immediate task at hand; to do what North, in his classic text, exhorts us to do and develop the writer, and not just the writing (North, 1984).

At this point, the tutor engages the student in discussions about the genre of the task at hand. For example, an argumentative essay would require their understanding of not just how to write such an essay, but also why certain aspects of it must take a particular dimension, such as the use of evidence, and the structuring of the paragraphs to express claims and evidence related to reasoning. At this stage, tutors are expected to lay emphasis on the need for student writers to understand their own writing style, as well as their own knowledge and application of writing conventions, taking the academic discourse of their specific disciplines into consideration, and heightening their awareness of this.

Writing-related questions need to be carefully balanced with task-related questions: if the focus is too much on the content and form of the immediate assignment, students may connect all their learning only to that single context, creating in students a potential dependence on this kind of help with every assignment. But, if the questions are too much about generalizable notions of genre characteristics, or why we write introductions or paragraphs this way or that depending on the discipline, students may not learn enough in the tutorial to help them make progress with the task at hand. Tutors thus need guidance, and need to lean on their own experience as writers, to learn how, when and why to ask particular questions to create an environment conducive for student learning, in the shorter and longer term.

\section{Implications of questioning on student writers, peer tutors, and the writing centre community}

The ways in which the UWC Writing Centre has used questioning in writing tutorials has over the years left imprints of varying degrees on both students and tutors, imprints that are highly replicable. One outstanding imprint for students is that of ownership of their writing (see Brooks, 1991, a classic text). This is evidenced in students' feedback, where they focus on how they can keep working on their own essays post-tutorial: 'The tutor was helpful and he explained everything that I didn't understand in my assignment. I now know what I need to do to improve my writing', and, 'I now understand how to construct an essay and include factors that are important and also constructing an interesting paragraph. I received constructive criticism that built my writing skills'. Putting the responsibility for the writing into the hands of the student writers, and basing the conversation on different kinds of revealing or exploratory questions, has the effect of making students feel more knowledgeable and capable. They may well return to the Writing Centre, but hopefully they will return with 
different tasks, different questions and a sense of how they are growing as writers over time.

Another key effect of a more conscious approach to questioning is the potential for 'replicability', such that students leave the writing centre able to understand and explain not just the ways in which the present assignment can be improved, but how this learning can be taken on to future assignments. Replication would mean reducing dependency on the writing centre, and may make it possible for students to help their peers and develop a more 'writing intensive' culture within their courses or modules. A balance between focusing on the specific task at hand, and lifting the focus above that task to look at issues contributing to longer-term development, such as explaining why we write particular genres the way we do (and how they might be challenged perhaps), is vital to ensuring that learning happens cumulatively for students (Clarence, 2017).

A further outcome of a dialogical approach to writing consultations, using the kinds of questioning reflected on above, is shared power between peer tutors and student writers. Apart from making the student writer accept responsibility and have a voice in their writing, the kinds of questions tutors ask and the corresponding answers give student writers shared power in terms of controlling the pace and form of the writing tutorial (Shabanza, 2017). This experience - of learning to express their own views and take responsibility for their writing in a supportive space - may make students more able to claim and use their voice with other tutors and lecturers, hence becoming more critical and active in their thinking and writing. Asking and answering questions, and giving students space and time to think and talk about their work challenges the more traditional, hierarchical power dynamics present in other

contexts within the university (Harris, 1995; Nichols, 2017). This makes the role of questioning, and the ability of the writing centre - and peer tutoring more generally - to use this tool to assist students to take ownership of their own learning process so valuable, and worthy of consideration.

Thompson (2009) adds that questioning contributes to developing student writers' motivation and confidence, attributes that they are likely to take into their future academic and writing careers. The ability of the writing centre to challenge the classroom approach enables student writers to have the courage to share their own thoughts and challenges more freely, knowing that they will not be judged or criticized. Students enter consultations with different levels of confidence and motivation, but generally leave the centre better off or different than they were when they first arrived, based on the kinds of student-focused, question-oriented conversations they are a part of.

There are also benefits for tutors as well. The use of questioning assists tutors to become more coherent and organized in their own writing endeavours, since they indirectly learn by teaching (Topping, 1998). The ability of the tutor to plan the questions, and evaluate students' responses, enhances their own cognitive development. In other words, as tutors 
reflect on student writing, and the kinds of questions they could ask students in tutorials, they are able to approach their own writing through a critical lens, using the same kinds of questions to improve their own thinking and writing.

\section{Conclusion}

Questioning plays an invaluable role in shaping the work of a writing centre in higher education. The ability of the questioning approach to create engagement, participation, and a truly student-centred conversational space about writing presents many advantages to both peer tutors and student writers. However, using the different types of questions highlighted in this paper to structure productive conversations with student writers is not an easy, linear task. Students come to the writing centre, or to a tutoring environment, with different concerns about their academic work, and need to meet at the point where they are taken forward for their learning to be truly empowering and relevant. The role of questioning is to help tutors to meet students where they are, assess with them the next steps in the process, and support them as they work out how to take these steps to move forward.

Although this paper has focused on the work of a writing centre in using questions, and the resulting dialogic approach to peer tutoring to enhance student learning, we believe that aspects of our argument have relevance for peer tutoring in higher education more generally. All peer tutors should be approaching students as peers, rather than as lecturers or experts; all tutorials should be based on engaging students in their own learning, giving them space to think, talk and reflect on their academic work as they take responsibility for it. Thus, it is our hope that those tutoring or working with tutors in and outside of writing centres will rethink the role of questioning within their tutorial spaces, and explore within their own contexts the kinds of questions that are most useful in eliciting greater student participation, ownership and learning.

\section{Disclosure statement}

No potential conflict of interest was reported by the authors.

\section{Notes on contributors}

Paul Nwati Munje is a postdoctoral fellow with the Centre for Research on Higher Education and Development (CHRED), at the University of the Free State. His research is focused on performance, educational leadership and management, and policy. He tutored at the UWC Writing Centre during his recent $\mathrm{PhD}$ study.

Robert Doya Nanima is a Lecturer in the Faculty of Law at the University of the Western Cape, and his research areas are Public Law and Criminal Law. He tutored in the UWC Writing Centre during his MA and PhD study.

Sherran Clarence is an honorary research associate in the Centre for Postgraduate Studies at Rhodes University, and her research focuses on academic literacies, writing in higher education, and academic staff development. 


\section{References}

Archer, A. (2010). Challenges and potentials for Writing Centres in South African tertiary institutions. South African Journal of Higher Education, 24(4), 495-510.

Beard, C., Clegg, S., \& Smith, K. (2007). Acknowledging the affective in higher education. British Educational Research JournalI, 33(2), 235-252.

Bock, K. (1989). Closed-class immanence in sentence production. Cognition, 31(2), 163186. Bourdieu, P., \& Passeron, J. C. (1990). Reproduction in education, society and culture (Vol. 4). London: Sage publications.

Brooks, J. (1991). Minimalist tutoring: Making the student do all the work. The Writing Lab Newsletter, 15(6), 1-4.

Brown, K. (2008). Breaking into the Tutor's toolbox: An investigation into strategies used in writing center tutorials. University of Louisville. Louisville: ProQuest Dissertations Publishing.

Capdevielle, M. (2012). Why do you ask? Questioning the question in the writing center. Retrieved February 12, 2016, from http://writing.wisc.edu/blog/?p=2112

Carter, S. (2009). The writing center paradox: Talk about legitimacy and the problem of institutional change. College Composition and Communication, 61(1), 133-152.

Clarence, S. (2011). Making inter-disciplinary spaces for talk about and change in student writing and literacy development. Teaching in Higher Education, 17(2), 127-137.

Clarence, S. (2017). A relational approach to building knowledge through academic writing: Facilitating and reflecting on peer writing tutorials. In S. Clarence \& L. Dison (Eds.), Writing centres in higher education. Working in and across the disciplines (pp. 67-80). Stellenbosch: SUNPress.

Deane, M., \& Ganobcsik-Williams, L. (2012). Providing a hub for writing development. In C. Thaiss, G. Brauer, P. Carlino, L. Ganobcsik-Williams, \& A. Sinha (Eds.), Writing programs worldwide: Profiles of academic writing in many places (pp. 189201). Fort Collins, Colorado: Parlor Press.

Deyi, S. (2011). Feedback or feed-forward? Students negotiating their academic identities in a writing centre. In A. Archer \& R. Richards (Eds.), Changing spaces: Writing centres and access to higher education (pp. 47-58). Stellenbosch: SUN Press.

Dison, L., \& Clarence, S. (2017). Introduction. In S. Clarence \& L. Dison (Eds.), Writing centres in higher education. Working in and across the disciplines (pp. 5-16). Stellenbosch: SUNPress.

Dison, L., \& Mendelowitz, B. (2017). Reflecting on writing centre practice through students' experiences of a contextualised writing centre. In S. Clarence \& L. Dison (Eds.), Writing centres in higher education. Working in and across the disciplines (pp. 193-207). Stellenbosch: SUNPress.

Habib, A. (2016). Reimagining the African University and critically analysing the struggle for its realisation. Paper presented at the "African Voices @UCL" lecture at University College London. January 25. Retrieved June 3, 2017, from https://www.wits.ac.za/news/latest-news/in-their-own-words/2016/2016- 
01/reimagining-the-south-african-university-and-critically-analysing-the-strugglefor-its-realisation.html\#sthash.AnS8gR4a.dpuf.

Harris, M. (1995). Talking in the middle: Why writers need writing tutors. College English, 57 (1), 27-42.

Hathaway, J. (2015). Developing that voice: locating academic writing tuition in the mainstream of higher education. Teaching in Higher Education, 2O(5), 506-517.

Jacobs, C. (2015). Opening up the curriculum: Moving from the normative to the transformative in teachers' understandings of disciplinary literacy practices. In T. Lillis, K. Harrington, M. R. Lea, \& S. Mitchell (Eds.), Working with academic literacies: Case studies towards transformative practice (pp. 131141). Colorado: Parlor Press/WAC Clearinghouse.

Jones, R. H., Garralda, A., DLi, C. S., \& Lock, G. (2006). Interactional dynamics in online and face-to-face peer-tutoring sessions for second language writers. Journal of Second Language Writing, 15(1), 1-23.

Lewin, T., \& Mawoyo, M. (2014). Student access and success: Issues and interventions in South African Universities. Cape Town: The South African Institute for Advancement. $\quad$ Retrieved June 3, 2017, from http://kresge.org/sites/default/files/Issues\%20and\%2oInterventions\% 20in\%2oSouth\%20African\%2oUniversities.pdf

Lillis, T., Harrington, K., Lea, M. R., \& Mitchell, S. (2015). Introduction. In T. Lillis, K. Harrington, M. R. Lea, \& S. Mitchell (Eds.), Working with academic literacies: Case studies towards transformative practice (pp. 3-22). Colorado: Parlor Press/WAC Clearinghouse.

Limberg, H., Modey, C., \& Dyer, J. (2016). So what would you say your thesis is so far? Tutor questions in writing tutorials. Journal of Writing Research, 7(3), 371-396.

Mitoumba-Tindy, H. (2017). Working in the interspace between subject knowledge and academic literacies: Writing centres as a zone of proximal development. In S. Clarence \& L. Dison (Eds.), Writing centres in higher education. Working in and across the disciplines (pp. 67-80). Stellenbosch: SUNPress.

Nichols, P. (2017). Writing democracy: From writing centres to writing fellows to writing intensive courses in a university-wide writing programme. In S. Clarence \& L. Dison (Eds.), Writing Centres in Higher Education. Working in and across the disciplines (pp. 35-48). Stellenbosch: SUNPress.

North, S. M. (1984). The idea of a writing center. College English, 46(5), 433-446.

O'Shea, S., Lysaght, P., Roberts, J., \& Harwood, V. (2016). Shifting the blame in higher education - social inclusion and deficit discourses. Higher Education Research and Development, 35(2), 322-336.

O'Sullivan, I., \& Cleary, L. (2014). Peer-tutoring in academic writing: The infectious nature of engagement. Journal of Academic Writing, 4(1), 52-65.

Reddy, T. (2004). Higher education and social transformation: South Africa case study. Pretoria: Council on Higher Education. Retrieved March 11, 2017, from http://www.che.ac.za/sites/

default/files/publications/HEandSocialTransformationReport_25Feb2004.pdf 
Shabanza, K. J. (2017). Enhancing reflection on writing: Using group writing consultations to develop meta-awareness of disciplinary writing. In S. Clarence \& L. Dison (Eds.), Writing centres in higher education. Working in and across the disciplines (pp. 161174). Stellenbosch: SUNPress.

Smit, R. (2012). Towards a clearer understanding of student disadvantage in higher education: Problematising deficit thinking. Higher Education Research \& Development, 31(3), 369-380.

Thompson, I. (2009). Scaffolding in the writing center: A microanalysis of an experienced tutor's verbal and written tutoring strategies. Written CommunicationI, 26(4), 417-453. Thompson, I. S., \& Mackiewicz, J. (2014). Questioning in writing center conferences. The

Writing Center Journal, 33(2), 37-70.

Topping, K. J. (1998). Peer tutoring for flexible and effective adult learning. In P. Sutherland (Ed.), Adult learning: A reader (pp. 106-121). London: Kogan Page.

van Heerden, M., Clarence, S., \& Bharuthram, S. (2017). What lies beneath: Exploring the deeper purposes of feedback on student writing through considering disciplinary knowledge and knowers. Assessment \& Evaluation in Higher Education, 42(6), 967-977.

Wolpe, H. (1995). The debate on University Transformation in South Africa: The case of the University of the Western Cape. Comparative Education, 31(2), 275-292.

Yeats, R., Reddy, P., Wheeler, A., Senior, C., \& Murray, J. (2010). What a difference a writing centre makes: A small scale study. Education \& Training, 52(6/7), 499-507. 